\title{
Factors Influencing Functional Heterogeneity in Human Mucosa- Associated Invariant T Cells
}

\author{
Joana Dias', Caroline Boulouis', Michał J. Sobkowiak', Kerri G. Lal1,2,3, Johanna Emgård', \\ Marcus Buggert', Tiphaine Parrot ${ }^{1}$, Jean-Baptiste Gorin ${ }^{1}$, Edwin Leeansyah ${ }^{1,4}$ \\ and Johan K. Sandberg ${ }^{1 *}$
}

${ }^{1}$ Center for Infectious Medicine, Department of Medicine, Karolinska Institutet, Karolinska University Hospital Huddinge, Stockholm, Sweden, ${ }^{2}$ U.S. Military HIV Research Program, Walter Reed Army Institute of Research, Silver Spring, MD, United States, ${ }^{3}$ Henry M. Jackson Foundation for the Advancement of Military Medicine, Bethesda, MD, United States, ${ }^{4}$ Program in Emerging Infectious Diseases, Duke-National University of Singapore Medical School, Singapore, Singapore

OPEN ACCESS

Edited by: Luc Van Kaer, Vanderbilt University, United States

Reviewed by:

Derya Unutmaz,

Jackson Laboratory for

Genomic Medicine,

United States

Agnes Lehuen,

Institut National de la Santé et de la Recherche Médicale

(INSERM), France

Asako Chiba,

Juntendo University, Japan

${ }^{*}$ Correspondence:

Johan K. Sandberg johan.sandberg@ki.se

Specialty section:

This article was submitted

to T Cell Biology,

a section of the journal

Frontiers in Immunology

Received: 26 April 2018

Accepted: 27 June 2018

Published: 10 July 2018

Citation:

Dias J, Boulouis C, Sobkowiak MJ, Lal KG, Emgård J, Buggert M,

Parrot T, Gorin J-B, Leeansyah E and Sandberg JK (2018) Factors

Influencing Functional Heterogeneity

in Human Mucosa-Associated

Invariant T Cells.

Front. Immunol. 9:1602.

doi: 10.3389/fimmu.2018.01602
Mucosa-associated invariant T (MAIT) cells are unconventional innate-like T cells that recognize microbial riboflavin metabolites presented by the monomorphic $\mathrm{MHC}$ class I-related (MR1) molecule. Despite the high level of evolutionary conservation of MR1 and the limited diversity of known antigens, human MAIT cells and their responses may not be as homogeneous as previously thought. Here, we review recent findings indicating that MAIT cells display microbe-specific response patterns with multiple layers of heterogeneity. The natural killer cell receptor CD56 marks a MAIT cell subset with distinct response profile, and the $T$ cell receptor $\beta$-chain diversity influences responsiveness at the single cell level. The MAIT cell tissue localization also influences their response profiles with higher IL-17 in tissue-resident MAIT cells. Furthermore, there is emerging evidence that the type of antigen-presenting cells, and innate cytokines produced by such cells, influence the quality of the ensuing MAIT cell response. On the microbial side, the expression patterns of MR1-presented antigenic and non-antigenic compounds, expression of other bioactive microbial products, and of innate pattern recognition ligands all influence downstream MAIT cell responses. These recent findings deepen our understanding of MAIT cell functional diversity and adaptation to the type and location of microbial challenge.

Keywords: mucosa-associated invariant T cells, MHC class I-related, CD56, cytokines, microbial immunity, antibacterial immunity, mucosal immunology

\section{INTRODUCTION}

Mucosa-associated invariant $\mathrm{T}$ cells are unconventional $\mathrm{T}$ cells operating on the border between the innate and adaptive immunity and respond promptly in an innate-like manner to antigens presented by the MHC class I-related (MR1) protein $(1,2)$. Human mucosa-associated invariant T (MAIT) cells express a semi-invariant T cell receptor (TCR) characterized by the uniform use of the V $\alpha 7.2$ segment paired with $J \alpha 12,20$, or 33 , whereas the $\beta$-chain diversity is broader but still limited (3-7).

The naturally occurring MR1-presented MAIT cell agonists identified to date are metabolites derived from the riboflavin biosynthesis pathway $(8,9)$. This limited set of antigens coupled with the high evolutionary conservation of MR1 (10) has favored the notion that MAIT cells may be functionally homogeneous and responding in a largely undifferentiated manner to microbes capable of riboflavin production. However, recent studies have demonstrated that MAIT cells are 
in fact fairly heterogeneous in their phenotype and function, and that their response patterns are influenced by a range of factors.

\section{MAIT CELL RESPONSE PATTERNS VARY BASED ON MICROBIAL STIMULI AND TISSUE LOCALIZATION}

We recently found that peripheral blood MAIT cells respond differently to distinct microbes in both the quality and quantity of cytokines produced (7). The Gram-negative bacterium Escherichia coli induced production of interferon (IFN) $\gamma$ and tumor necrosis factor (TNF), as well as TCR downregulation, at significantly higher levels than the opportunistic fungus Candida albicans, and the MAIT cell polyfunctional cytokine profile significantly differed in response to these microbes (7). Moreover, several studies have provided evidence that MAIT cell effector functions vary based on tissue localization. Upon bacterial stimulation, peripheral blood and gastric MAIT cells produce IFN $\gamma$ and TNF, and degranulate $(2,4,11-15)$, whereas MAIT cells from the female genital mucosa display a bias toward production of interleukin (IL)-17 and IL-22 (16). Moreover, in response to Mycobacterium tuberculosis stimulation, MAIT cells from tuberculous pleural effusions display an enhanced capacity to produce IFN $\gamma$, IL-17F, and granzyme B than circulating MAIT cells (17). Upon phorbol myristate acetate and ionomycin stimulation, MAIT cells from the liver and adipose tissue produce more IL-17 and IL-10, respectively, than their peripheral blood counterparts $(18,19)$. Data from mouse models further support a role of MAIT cells in the control of type 1 diabetes via maintenance of gut integrity and control of anti-islet autoimmune responses (20), as well as of pulmonary infection by Francisella tularensis live vaccine strain (LVS) $(21,22)$. Overall, these findings suggest the existence of MAIT cell response patterns that vary with tissue localization and depend on the microbes encountered.

Antimicrobial immune responses are an outcome of the interplay between effector cells, antigen-presenting cells (APCs), and microbes. Recent findings have indicated that MAIT cells are phenotypically heterogeneous and comprise functionally distinct subsets (7). Thus, the functional compartmentalization of the MAIT cell population, together with distinct characteristics of APCs and microbes, may influence MAIT cell responses upon microbial encounter.

\section{MAIT CELLS-NOT AS HOMOGENEOUS AS THEY FIRST MAY SEEM}

Adult peripheral blood MAIT cells were long considered phenotypically homogeneous in that they express a restricted semiinvariant TCR $\alpha$-chain and predominantly exhibit a $\mathrm{CD} 45 \mathrm{RO}^{+}$ $\mathrm{CCR}^{-}{ }^{-} \mathrm{CD} 62 \mathrm{~L}^{-} \mathrm{CD} 28^{+}$effector memory phenotype $(3,7,23,24)$, as determined by individual assessment of surface receptors $(23,24)$ and by screening of their surface immune-proteome (7). However, MAIT cells vary in their expression of TCR V $\beta$ segments (3-7), and of the natural killer (NK) cell-associated receptor CD56 (7). Thus, the discovery of these phenotypically distinct MAIT cell populations suggested the existence of subsets that could potentially exhibit different functional properties.

\section{THE TCR $\beta$-CHAIN COMPOSITION INFLUENCES MAIT CELL ANTIMICROBIAL RESPONSES}

Although less diverse than that of other $\mathrm{T}$ cells $(5,6)$, the $\mathrm{V} \beta$ usage of MAIT cells adds some diversity to their overall TCR $\beta$-chain repertoire. We observed that the $\mathrm{V} \beta$ segment expression can influence MAIT cell responses, as MAIT cells expressing $\mathrm{V} \beta 8^{+}, \mathrm{V} \beta 13.1^{+}$, and $\mathrm{V} \beta 13.6^{+}$were hyporesponsive to E. coli, and $\mathrm{V} \beta 13.2^{+}$MAIT cells were slightly hyperresponsive to $C$. albicans when compared with the total MAIT cell population (7). LopezSagaseta et al. $(25,26)$ had previously reported different binding affinities between MAIT cell TCRs with different V $\beta$ segments and MR1 in complex with a MAIT cell agonist. Thus, while the semi-invariant $\alpha$-chain is indispensable for TCR recognition of MR1-ligand complexes $(25,27)$, the TCR $\beta$-chain may influence MAIT cell antimicrobial responses by fine-tuning the overall TCR-ligand-MR1 interaction. In light of the aforementioned findings, one can speculate that localization or accumulation of $\mathrm{V} \beta 13.2^{+}$MAIT cells, which comprise a significant proportion of the total MAIT cell population (7), at sites of C. albicans colonization, such as the genitourinary tract (28), could boost local immune responses against this opportunistic pathogen.

Mucosa-associated invariant $\mathrm{T}$ cell subpopulations defined by $\mathrm{V} \beta$ expression also have differential proliferative capacity in vitro. MAIT cells that express the more abundant V $\beta$ 's proliferate more in vitro in response to E. coli than the less abundant ones (7). This finding raises the possibility that the in vivo interactions with microbes believed to drive the expansion of MAIT cells from the low frequencies seen in cord blood also shape the $V \beta$ repertoire by selectively driving the expansion of more responsive MAIT cell subsets in an antigen-dependent manner. If this is the case, the MAIT cell TCR repertoire might be influenced by vaccination strategies that expose individuals to microbial antigens. In agreement with this, Howson et al. (29) recently reported a preferential expansion of certain MAIT cell clonotypes in human volunteers challenged with Salmonella enterica serovar Paratyphi A (29). Interestingly, the MAIT cell clonotypes that expanded in vivo were more strongly activated in vitro in an MR1-dependent manner than those that contracted during infection, potentially due to higher functional avidity between their TCRs and MR1 ligands (29). Thus, the MAIT cell TCR $\beta$-chain repertoire may function as a bacterial infection signature of any given individual. Furthermore, factors such as the geographic location, diet, or medication usage [all of them known to affect the microbiota $(30,31)]$ might shape the MAIT cell TCR $\beta$-chain repertoire as well. Hinks et al. (32) reported that the levels of MAIT cells in peripheral blood and bronchial tissues were affected in steroid-treated chronic obstructive pulmonary disease patients when compared with non-steroid-treated patients (32). However, it remains to be investigated if this or any other factor influences the MAIT cell TCR $\beta$-chain repertoire through its effect on the microbiota. 


\section{CD56 MARKS A MAIT CELL SUBSET WITH ENHANCED INNATENESS}

A proportion of human MAIT cells in peripheral blood express the NK cell marker CD56 (7). Interestingly, the CD56-expressing MAIT cells have a higher capacity to respond to IL-12 and IL-18 than their negative counterparts (7). This can possibly be explained by their higher expression levels of IL-12R and IL-18R, as well as higher levels of the transcription factors PLZF, Eomes, and T-bet (7). The higher responsiveness of CD56 $6^{+}$MAIT cells to innate cytokines may make them more efficient in mounting MR1-independent responses during viral and bacterial infections, as well as sterile inflammatory conditions. In addition, CD56 ${ }^{+}$MAIT cells are reportedly more abundant in the liver than in peripheral blood $(19,33)$. Whether this MAIT cell subset has protective, pathogenic, or modulatory roles in liver diseases such as viral hepatitis remains to be determined.

In summary, the type and magnitude of effector functions mounted in response to stimuli can be influenced by factors intrinsic to the MAIT cells: the TCR $\beta$-chain composition and CD56 expression (Figure 1). Thus, the relative amounts of CD56 ${ }^{+}$ and CD56- MAIT cells and of V $\beta$-defined MAIT cell subsets, the latter potentially already determined by previous microbial encounters in vivo, might play an important role in determining how the MAIT cell compartment will respond to a new antigenic challenge.

\section{DIFFERENTIAL DEPENDENCE ON MR1 FOR MAIT CELL CYTOKINE PRODUCTION}

At steady state, MR1 is mostly retained intracellularly (34-37) and traffics to the cell surface upon ligand availability and APC activation $(34,36,38)$. Interestingly, blocking experiments have revealed differential MR1-dependency in MAIT cell responses (7). In responses to both E. coli and C. albicans, most IFN $\gamma$ and virtually all TNF produced by MAIT cells was dependent on the TCR-MR1 interaction (7). However, a small proportion of IFN $\gamma$ was produced in an MR1-independent manner (7). The dependency on MR1-mediated antigen presentation for MAIT cell production of TNF suggests tight regulation of their pro-inflammatory responses. This may be an important regulatory mechanism to prevent MAIT cell activation in response to riboflavin biosynthesis-competent commensal microbes that do not actively produce MAIT cell agonists at steady state, but still reside close to MAIT cells. Moreover, the low levels of MR1 on most cells at steady state may prevent continuous activation of

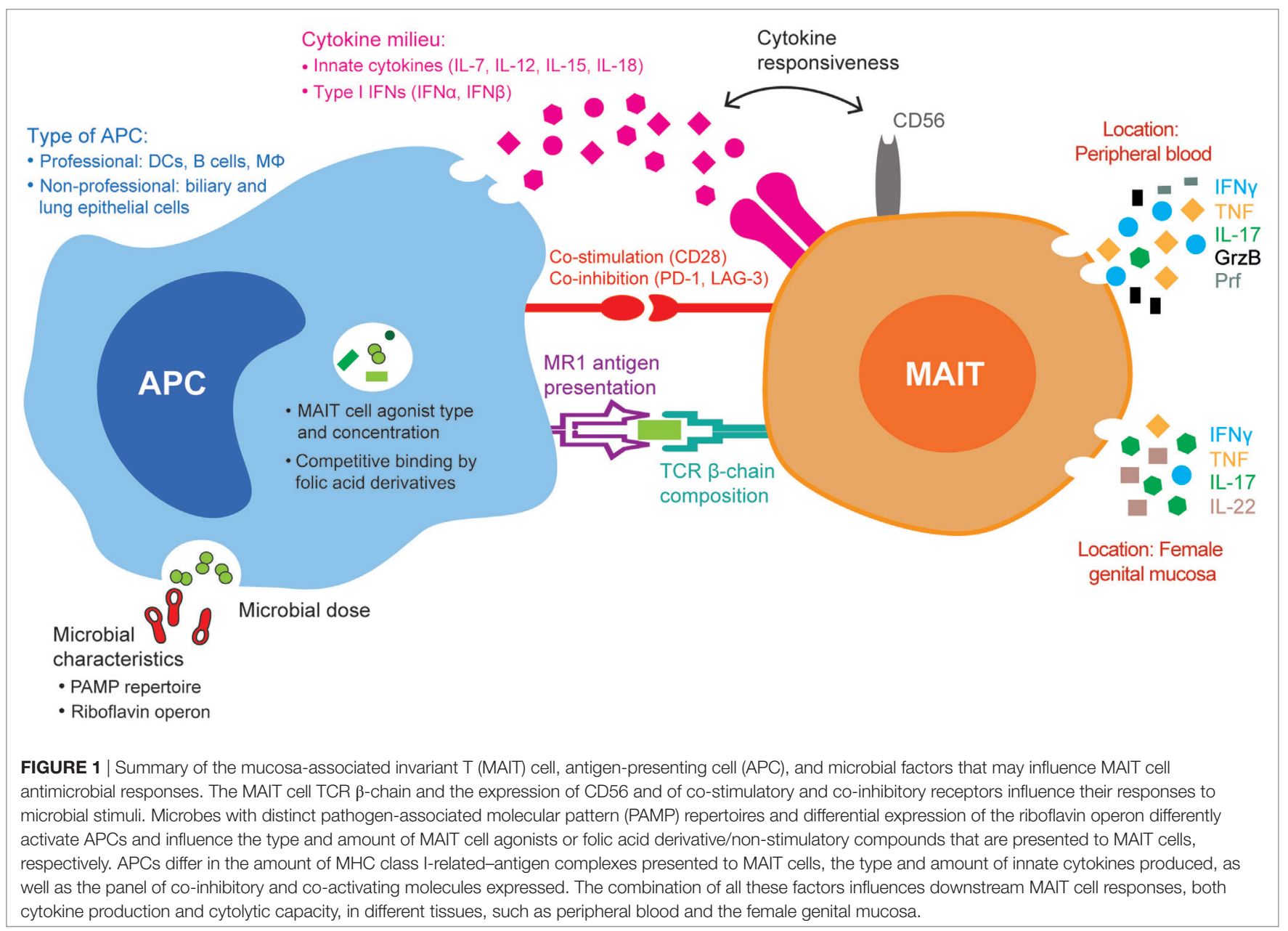


MAIT cells by MR1 ligands from commensal microbes. As MR1 can bind extracellular ligands directly on the cell surface, these ligands, even if present at homeostatic levels, could otherwise lead to unnecessary MAIT cell pro-inflammatory responses (36).

\section{INNATE CYTOKINES ACTIVATE MAIT CELLS IN AN MR1-INDEPENDENT MANNER}

Microbes activate APCs to secrete cytokines, such as IL-12 and IL-18, which induce IFN $\gamma$ production by MAIT cells independently of TCR signaling and MR1 (39). In agreement with these initial findings, Jesteadt et al. (40) recently reported different MAIT cell responses to two microbes that differ in their capacity to activate the inflammasome, a proinflammatory innate immune system collection of receptors and sensors that involve activation of caspase- 1 and inflammatory molecules to both microbes and host-derived proteins $(40,41)$. In contrast to Francisella tularensis LVS, Francisella novicida is a strong inflammasome activator that induced high levels of IL-18 production by macrophages and subsequent high levels of IFN $\gamma$ production by murine MAIT cells (40). Moreover, the magnitude of the in vitro IFN $\gamma$ production in response to F. novicida was directly influenced by the concentration of IL-18 in the cultures (40). Therefore, one can expect differential MAIT cell responses to microbes with different ability to induce IL-18 production by the APCs.

Other cytokines can have a range of effects on peripheral blood MAIT cells. In the absence of microbial stimulation, IL-7 induces GrzB and upregulates Prf expression without concomitant production of cytokines (14), whereas IL-15 in combination with IL-18 and/or IL-12 induces IFN $\gamma$ and GrzB production (42-44). Upon stimulation with suboptimal doses of E. coli, both IL-7 and IL-15 augment cytokine and cytolytic molecule expression by MAIT cells $(14,42)$. Moreover, the combination of MR1 antigen presentation with either IL-12, or IL-7 and IL-12, induces GrzB production by MAIT cells in response to E. coli (13) or nontypeable Haemophilus influenzae (NHTi), respectively (45). Thus, it is plausible that APCs shape MAIT cell antimicrobial responses through the cytokines they produce upon microbial-mediated activation. In fact, the capacity of MAIT cells to be activated by cytokines alone underlies their ability to respond in vitro to several viruses, including dengue virus, influenza virus, and hepatitis C virus, in a process dependent on IL-12 and IL-18, IL-18 alone, and IL-18 and IL-15, respectively $(43,46)$. In addition, both IFN $\alpha$ and IFN $\beta$ were shown to activate MAIT cells $(43,47)$ and further contribute to the MAIT cell response to HCV (43). Moreover, MAIT cells can respond to the superantigen staphylococcal enterotoxin B independently of MR1 and in an IL-12, IL-18, TCR $\mathrm{V} \beta$, and HLA class II-dependent manner $(48,49)$.

\section{DIFFERENT TYPES OF APCS VARY IN KEY FUNCTIONS REQUIRED FOR MAIT CELL ACTIVATION}

As the MR1 gene is ubiquitously expressed (50-52), many different cell types are able to present antigen to MAIT cells.
The repertoire of innate cytokines and the extent to which MR1 is upregulated and brought to the cell surface upon activation and ligand availability vary not only with the type of stimulation but also with the type of $\operatorname{APC}(38,53)$. Professional APCs (DCs, macrophages, and B cells) are efficient in microbe internalization and processing, as well as in delivering costimulatory signals to T cells. Kurioka et al. showed that the MR1-dependency of the MAIT cell response to pneumococci varied with the type of APC used (54). While the MAIT cell response in the presence of monocytes was MR1-independent, it was partially MR1-dependent in the presence of monocytederived macrophages (54). We previously observed that the addition of anti-CD28 to E. coli-fed monocytes cultured with $\mathrm{V} \alpha 7.2^{+}$cells boosted MAIT cell IFN $\gamma$ production (55), thus indicating that monocytes are not intrinsically efficient in delivering co-stimulatory signals and that the magnitude of the MAIT cell response varies with the degree of co-stimulation provided.

In conclusion, several aspects of the APC shape the magnitude and quality of MAIT cell antimicrobial responses. Such APCintrinsic factors include the surface expression of MR1-antigen complexes, the innate cytokines produced, and the panel of costimulatory and co-inhibitory receptors expressed upon microbial exposure (Figure 1). MAIT cells are likely to encounter different APCs in vivo, and their responses will ultimately be influenced by the type and representation of APCs.

\section{MICROBE GROWTH CONDITIONS INFLUENCE THE PRODUCTION OF MR1-PRESENTED LIGANDS}

Mucosa-associated invariant $\mathrm{T}$ cells sense microbes through antigens presented by MR1 on the surface of APCs. The naturally occurring activating antigens identified thus far belong to the riboflavin biosynthesis pathway $(8,9)$, expressed in many different species of bacteria and fungi $(56,57)$. However, the ability of a microbe to activate MAIT cells depends not only on its capacity to produce MR1-presented agonists but also on whether MAIT cell non-stimulatory MR1-binding compounds are also produced and to what extent.

The type and concentration of MR1-presented compounds vary with the microbial growth conditions. 5-(2oxopropylideneamino)-6-D-ribitylaminouracil (5-OP-RU), the most potent MAIT cell agonist identified thus far, requires the riboflavin intermediate precursor 5-amino-6-D-ribitylaminouracil (5-A-RU) and either methylglyoxal or glyoxal for its generation (9), whereas natural MAIT cell non-stimulatory compounds derive from folic acid $(8,58,59)$. The concentration of these precursor molecules at effector sites will likely dictate the amount of antigenic and non-antigenic MR1-presented compounds. It was recently shown that Streptococcus pneumoniae clinical isolates respond to exogenous availability of riboflavin by downregulating the ribD gene (which encodes the enzyme pyrimidine deaminase/ reductase essential for the production of 5-A-RU), with a consequent decrease in MAIT cell stimulatory potential (60). On the other hand, heat-stress was shown to induce the riboflavin 
operon in pneumococci, with upregulation of the riboflavin pathway genes within 2-4 h under such conditions (54).

It is also possible that other, yet unknown MAIT cell antigens with different requisites for their formation exist. Meermeier et al. (61) reported that MR1-restricted non-classical TRAV1-2- (V $\left.\alpha 7.2^{-}\right)$ MAIT cells could be activated in an MR1-dependent manner by Streptococcus pyogenes, a riboflavin biosynthesis-incompetent microbe. This suggests that MR1 can present MAIT cell agonists other than riboflavin metabolites (61).

Other microbial products that are not presented by MR1 may also influence MAIT cell responses. For instance, lactate was shown to dampen $\mathrm{NK}$ and $\mathrm{T}$ cell activation in response to Staphylococcus aureus (62). Furthermore, short-chain fatty acids derived from bacterial fermentation, such as acetate, butyrate, and propionate, promote differentiation of $\mathrm{T}$ cells in a cytokine milieu-dependent manner $(63,64)$. Further investigation is required to determine if MAIT cells respond similarly to these microbial products.

In conclusion, the type of MR1-presented compounds and other bioactive microbial products will likely shape the functional characteristics of MAIT cell antimicrobial responses, as previously exemplified in in vitro competition experiments between MAIT cell activating and non-activating MR1-binding compounds $(58,59,65)$.

\section{MICROBIAL GENETIC BACKGROUND MAY PLAY A ROLE IN MAIT CELL RESPONSES}

Recent studies showed that different S. pneumoniae isolates activated MAIT cells to different extents, as assessed by CD69 upregulation and IFN $\gamma$ production $(54,60)$. Interestingly, Hartmann et al. found that $S$. pneumoniae isolates with similar MAIT cell activating properties grouped together with regard to their multilocus sequence type, suggesting a link between the MAIT cell response and microbial genetic background (60). The pneumococcus strain groups inducing higher levels of MAIT cell responses expressed significantly higher levels of the ribD gene and of MAIT cell ligands (60). Thus, differences in the genetic background between microbes influence their capacity to activate MAIT cells.

\section{THE MICROBIAL PAMP SIGNATURE AND PROPENSITY FOR PHAGOCYTOSIS CAN AFFECT MAIT CELL RESPONSES}

Different classes of microbes express distinct PAMPs, which can trigger toll-like receptors (TLRs) in APCs. Recently, Ussher et al. showed that the IFN $\gamma$ production by MAIT cells upon E. coli stimulation can be positively or negatively affected by pretreatment of APCs with TLR agonists (38). Therefore, the PAMP-TLR

\section{REFERENCES}

1. Treiner E, Duban L, Bahram S, Radosavljevic M, Wanner V, Tilloy F, et al. Selection of evolutionarily conserved mucosal-associated invariant $\mathrm{T}$ cells by MR1. Nature (2003) 422:164-9. doi:10.1038/nature01433 interaction might be another factor shaping MAIT cell antimicrobial responses.

Given that phagocytosis of particles depends on their size and shape (66), geometrically different microbes may have different propensity to be phagocytosed. Moreover, certain microbes contain a polysaccharide capsule, and variations in this structure are known to influence the rate of phagocytosis $(67,68)$. Thus, the intracellular microbial load may vary quite extensively with the type of microbe. Interestingly, by using S. enterica serovar Typhi and E. coli as microbes and a B cell line as APCs, SalernoGoncalves et al. found that the quality of the MAIT cell response depended on the microbial load (69).

In summary, MAIT cell antimicrobial responses can be influenced by several microbe-intrinsic factors, including their genetic background, physical characteristics, and PAMP repertoire, as well as their ability to produce MAIT cell antigens and other microbial products (Figure 1). These factors will not only influence MAIT cell functions but also dictate the amount of microbe that is required for optimal responses. In our study of MAIT cell responses to E. coli and C. albicans, we found that the optimal dose necessary for maximal MAIT cell activation, as assessed by CD69 upregulation and IFN $\gamma$ production, was much higher for E. coli than for C. albicans (7).

\section{CONCLUDING REMARKS}

In conclusion, numerous factors influence the quality and magnitude of MAIT cell antimicrobial responses, including the MAIT cell TCR $\beta$-chain composition, the expression of NK cellassociated receptors, and the TCR-ligand-MR1 interaction. Predominance of MAIT cell subsets with distinct effector functions at sites of microbial invasion and their co-localization with functionally heterogeneous conventional $\mathrm{CD} 4^{+}$and $\mathrm{CD} 8^{+} \mathrm{T}$ cells that recognize distinct antigens (70-72) builds multifaceted immune barriers of immunosurveillance able to efficiently target pathogens with different requirements for eradication.

\section{AUTHOR CONTRIBUTIONS}

JD, CB, EL, and JS wrote the manuscript; MS provided the figure; MS, KL, JE, MB, TP, and J-BG contributed to manuscript editing and revision; JD and JS revised the final manuscript.

\section{FUNDING}

This work was supported by grants to JS from the Swedish Research Council (2016-03052), the Swedish Cancer Society (CAN 2017/777), and the US National Institutes of Health (R01DK108350). JD was supported by Fundação para a Ciência e a Tecnologia (FCT) Doctoral Fellowship SFRH/BD/85290/2012, cofunded by the POPH-QREN and the European Social Fund (FSE).

2. Le Bourhis L, Martin E, Peguillet I, Guihot A, Froux N, Core M, et al Antimicrobial activity of mucosal-associated invariant T cells. Nat Immunol (2010) 11:701-8. doi:10.1038/ni.1890

3. Tilloy F, Treiner E, Park SH, Garcia C, Lemonnier F, De La Salle H, et al. An invariant $\mathrm{T}$ cell receptor alpha chain defines a novel TAP-independent major 
histocompatibility complex class Ib-restricted alpha/beta T cell subpopulation in mammals. J Exp Med (1999) 189:1907-21. doi:10.1084/jem.189.12.1907

4. Reantragoon R, Corbett AJ, Sakala IG, Gherardin NA, Furness JB, Chen Z, et al. Antigen-loaded MR1 tetramers define $\mathrm{T}$ cell receptor heterogeneity in mucosal-associated invariant T cells. J Exp Med (2013) 210:2305-20. doi:10.1084/jem.20130958

5. Lepore M, Kalinichenko A, Colone A, Paleja B, Singhal A, Tschumi A, et al. Parallel T-cell cloning and deep sequencing of human MAIT cells reveal stable oligoclonal TCRbeta repertoire. Nat Commun (2014) 5:3866. doi:10.1038/ ncomms 4866

6. Fergusson JR, Smith KE, Fleming VM, Rajoriya N, Newell EW, Simmons R, et al. CD161 defines a transcriptional and functional phenotype across distinct human T cell lineages. Cell Rep (2014) 9:1075-88. doi:10.1016/j.celrep. 2014.09.045

7. Dias J, Leeansyah E, Sandberg JK. Multiple layers of heterogeneity and subset diversity in human MAIT cell responses to distinct microorganisms and to innate cytokines. Proc Natl Acad Sci U S A (2017) 114:E5434-43. doi:10.1073/ pnas. 1705759114

8. Kjer-Nielsen L, Patel O, Corbett AJ, Le Nours J, Meehan B, Liu L, et al. MR1 presents microbial vitamin B metabolites to MAIT cells. Nature (2012) 491:717-23. doi:10.1038/nature11605

9. Corbett AJ, Eckle SB, Birkinshaw RW, Liu L, Patel O, Mahony J, et al. T-cell activation by transitory neo-antigens derived from distinct microbial pathways. Nature (2014) 509:361-5. doi:10.1038/nature13160

10. Tsukamoto K, Deakin JE, Graves JA, Hashimoto K. Exceptionally high conservation of the MHC class I-related gene, MR1, among mammals. Immunogenetics (2013) 65:115-24. doi:10.1007/s00251-012-0666-5

11. Leeansyah E, Ganesh A, Quigley MF, Sonnerborg A, Andersson J, Hunt PW, et al. Activation, exhaustion, and persistent decline of the antimicrobial MR1restricted MAIT-cell population in chronic HIV-1 infection. Blood (2013) 121:1124-35. doi:10.1182/blood-2012-07-445429

12. Cosgrove C, Ussher JE, Rauch A, Gartner K, Kurioka A, Huhn MH, et al. Early and nonreversible decrease of CD161++/MAIT cells in HIV infection. Blood (2013) 121:951-61. doi:10.1182/blood-2012-06-436436

13. Kurioka A, Ussher JE, Cosgrove C, Clough C, Fergusson JR, Smith K, et al. MAIT cells are licensed through granzyme exchange to kill bacterially sensitized targets. Mucosal Immunol (2015) 8:429-40. doi:10.1038/mi.2014.81

14. Leeansyah E, Svard J, Dias J, Buggert M, Nystrom J, Quigley MF, et al. Arming of MAIT cell cytolytic antimicrobial activity is induced by IL-7 and defective in HIV-1 infection. PLoS Pathog (2015) 11:e1005072. doi:10.1371/journal. ppat. 1005072

15. Booth JS, Salerno-Goncalves R, Blanchard TG, Patil SA, Kader HA, Safta AM, et al. Mucosal-associated invariant T cells in the human gastric mucosa and blood: role in Helicobacter pylori infection. Front Immunol (2015) 6:466. doi:10.3389/fimmu.2015.00466

16. Gibbs A, Leeansyah E, Introini A, Paquin-Proulx D, Hasselrot K, Andersson E, et al. MAIT cells reside in the female genital mucosa and are biased towards IL-17 and IL-22 production in response to bacterial stimulation. Mucosal Immunol (2017) 10:35-45. doi:10.1038/mi.2016.30

17. Jiang J, Chen X, An H, Yang B, Zhang F, Cheng X. Enhanced immune response of MAIT cells in tuberculous pleural effusions depends on cytokine signaling. Sci Rep (2016) 6:32320. doi:10.1038/srep32320

18. Carolan E, Tobin LM, Mangan BA, Corrigan M, Gaoatswe G, Byrne G, et al. Altered distribution and increased IL-17 production by mucosal-associated invariant T cells in adult and childhood obesity. JImmunol (2015) 194: 5775-80. doi:10.4049/jimmunol.1402945

19. Tang XZ, Jo J, Tan AT, Sandalova E, Chia A, Tan KC, et al. IL-7 licenses activation of human liver intrasinusoidal mucosal-associated invariant $\mathrm{T}$ cells. J Immunol (2013) 190:3142-52. doi:10.4049/jimmunol.1203218

20. Rouxel O, Da Silva J, Beaudoin L, Nel I, Tard C, Cagninacci L, et al. Cytotoxic and regulatory roles of mucosal-associated invariant $\mathrm{T}$ cells in type 1 diabetes. Nat Immunol (2017) 18:1321-31. doi:10.1038/ni.3854

21. Meierovics A, Yankelevich WJ, Cowley SC. MAIT cells are critical for optimal mucosal immune responses during in vivo pulmonary bacterial infection. Proc Natl Acad Sci U S A (2013) 110:E3119-28. doi:10.1073/pnas. 1302799110

22. Meierovics AI, Cowley SC. MAIT cells promote inflammatory monocyte differentiation into dendritic cells during pulmonary intracellular infection. J Exp Med (2016) 213:2793-809. doi:10.1084/jem.20160637
23. Martin E, Treiner E, Duban L, Guerri L, Laude H, Toly C, et al. Stepwise development of MAIT cells in mouse and human. PLoS Biol (2009) 7:e54. doi:10.1371/journal.pbio.1000054

24. Dusseaux M, Martin E, Serriari N, Peguillet I, Premel V, Louis D, et al. Human MAIT cells are xenobiotic-resistant, tissue-targeted, CD161hi IL-17-secreting T cells. Blood (2011) 117:1250-9. doi:10.1182/blood-2010-08-303339

25. Lopez-Sagaseta J, Dulberger CL, Crooks JE, Parks CD, Luoma AM, Mcfedries A, et al. The molecular basis for mucosal-associated invariant $\mathrm{T}$ cell recognition of MR1 proteins. Proc Natl Acad Sci U S A (2013) 110:E1771-8. doi:10.1073/ pnas. 1222678110

26. Lopez-Sagaseta J, Dulberger CL, Mcfedries A, Cushman M, Saghatelian A, Adams EJ. MAIT recognition of a stimulatory bacterial antigen bound to MR1. J Immunol (2013) 191:5268-77. doi:10.4049/jimmunol.1301958

27. Reantragoon R, Kjer-Nielsen L, Patel O, Chen Z, Illing PT, Bhati M, et al. Structural insight into MR1-mediated recognition of the mucosal associated invariant T cell receptor. J Exp Med (2012) 209:761-74. doi:10.1084/ jem. 20112095

28. Achkar JM, Fries BC. Candida infections of the genitourinary tract. Clin Microbiol Rev (2010) 23:253-73. doi:10.1128/CMR.00076-09

29. Howson LJ, Napolitani G, Shepherd D, Ghadbane H, Kurupati P, PreciadoLlanes L, et al. MAIT cell clonal expansion and TCR repertoire shaping in human volunteers challenged with Salmonella Paratyphi A. Nat Commun (2018) 9:253. doi:10.1038/s41467-017-02540-x

30. Yatsunenko T, Rey FE, Manary MJ, Trehan I, Dominguez-Bello MG, Contreras M, et al. Human gut microbiome viewed across age and geography. Nature (2012) 486:222-7. doi:10.1038/nature11053

31. Falony G, Joossens M, Vieira-Silva S, Wang J, Darzi Y, Faust $\mathrm{K}$, et al. Population-level analysis of gut microbiome variation. Science (2016) 352: 560-4. doi:10.1126/science.aad3503

32. Hinks TS, Wallington JC, Williams AP, Djukanovic R, Staples KJ, Wilkinson TM. Steroid-induced deficiency of mucosal-associated invariant $\mathrm{T}$ cells in the chronic obstructive pulmonary disease lung. implications for nontypeable Haemophilus influenzae infection. Am J Respir Crit Care Med (2016) 194: 1208-18. doi:10.1164/rccm.201601-0002OC

33. Kurioka A, Jahun AS, Hannaway RF, Walker LJ, Fergusson JR, SverremarkEkstrom E, et al. Shared and distinct phenotypes and functions of human CD161++ valpha7.2+ T cell subsets. Front Immunol (2017) 8:1031. doi:10.3389/ fimmu.2017.01031

34. Harriff MJ, Karamooz E, Burr A, Grant WF, Canfield ET, Sorensen ML, et al. Endosomal MR1 trafficking plays a key role in presentation of Mycobacterium tuberculosis ligands to MAIT cells. PLoS Pathog (2016) 12:e1005524. doi:10.1371/ journal.ppat.1005524

35. Huang S, Gilfillan S, Kim S, Thompson B, Wang X, Sant AJ, et al. MR1 uses an endocytic pathway to activate mucosal-associated invariant T cells. J Exp Med (2008) 205:1201-11. doi:10.1084/jem.20072579

36. Mcwilliam HE, Eckle SB, Theodossis A, Liu L, Chen Z, Wubben JM, et al. The intracellular pathway for the presentation of vitamin B-related antigens by the antigen-presenting molecule MR1. Nat Immunol (2016) 17:531-7. doi:10.1038/ni.3416

37. Yamaguchi H, Hashimoto K. Association of MR1 protein, an MHC class I-related molecule, with beta(2)-microglobulin. Biochem Biophys Res Commun (2002) 290:722-9. doi:10.1006/bbrc.2001.6277

38. Ussher JE, Van Wilgenburg B, Hannaway RF, Ruustal K, Phalora P, Kurioka A, et al. TLR signaling in human antigen-presenting cells regulates MR1-dependent activation of MAIT cells. Eur JImmunol (2016) 46:1600-14. doi:10.1002/ eji.201545969

39. Ussher JE, Bilton M, Attwod E, Shadwell J, Richardson R, De Lara C, et al. CD161++ CD8+ T cells, including the MAIT cell subset, are specifically activated by IL-12+IL-18 in a TCR-independent manner. Eur J Immunol (2014) 44:195-203. doi:10.1002/eji.201343509

40. Jesteadt E, Zhang I, Yu H, Meierovics A, Chua Yankelevich WJ, Cowley S. Interleukin-18 is critical for mucosa-associated invariant t cell gamma interferon responses to Francisella species in vitro but not in vivo. Infect Immun (2018) 86:e117-8. doi:10.1128/IAI.00117-18

41. Guo H, Callaway JB, Ting JP. Inflammasomes: mechanism of action, role in disease, and therapeutics. Nat Med (2015) 21:677-87. doi:10.1038/nm.3893

42. Sattler A, Dang-Heine C, Reinke P, Babel N. IL-15 dependent induction of IL-18 secretion as a feedback mechanism controlling human MAIT-cell effector functions. Eur J Immunol (2015) 45:2286-98. doi:10.1002/eji.201445313 
43. Van Wilgenburg B, Scherwitzl I, Hutchinson EC, Leng T, Kurioka A, Kulicke C, et al. MAIT cells are activated during human viral infections. Nat Commun (2016) 7:11653. doi:10.1038/ncomms11653

44. Slichter CK, Mcdavid A, Miller HW, Finak G, Seymour BJ, Mcnevin JP, et al. Distinct activation thresholds of human conventional and innate-like memory T cells. JCI Insight (2016) 1:e86292. doi:10.1172/jci.insight.86292

45. Wallington JC, Williams AP, Staples KJ, Wilkinson TMA. IL-12 and IL-7 synergize to control mucosal-associated invariant T-cell cytotoxic responses to bacterial infection. JAllergy Clin Immunol (2018) 141(6):2182-95.e6. doi:10.1016/j.jaci.2017.08.009

46. Loh L, Wang Z, Sant S, Koutsakos M, Jegaskanda S, Corbett AJ, et al. Human mucosal-associated invariant $\mathrm{T}$ cells contribute to antiviral influenza immunity via IL-18-dependent activation. Proc Natl Acad Sci U S A (2016) 113:10133-8. doi:10.1073/pnas.1610750113

47. Chiba A, Tamura N, Yoshikiyo K, Murayama G, Kitagaichi M, Yamaji K, et al. Activation status of mucosal-associated invariant $\mathrm{T}$ cells reflects disease activity and pathology of systemic lupus erythematosus. Arthritis Res Ther (2017) 19:58. doi:10.1186/s13075-017-1257-5

48. Shaler CR, Choi J, Rudak PT, Memarnejadian A, Szabo PA, Tun-Abraham ME, et al. MAIT cells launch a rapid, robust and distinct hyperinflammatory response to bacterial superantigens and quickly acquire an anergic phenotype that impedes their cognate antimicrobial function: defining a novel mechanism of superantigen-induced immunopathology and immunosuppression. PLoS Biol (2017) 15:e2001930. doi:10.1371/journal.pbio.2001930

49. Sandberg JK, Norrby-Teglund A, Leeansyah E. Bacterial deception of MAIT cells in a cloud of superantigen and cytokines. PLoS Biol (2017) 15:e2003167. doi:10.1371/journal.pbio.2003167

50. Hashimoto K, Hirai M, Kurosawa Y. A gene outside the human MHC related to classical HLA class I genes. Science (1995) 269:693-5. doi:10.1126/ science. 7624800

51. Riegert P, Wanner V, Bahram S. Genomics, isoforms, expression, and phylogeny of the MHC class I-related MR1 gene. J Immunol (1998) 161:4066-77.

52. Yamaguchi $\mathrm{H}$, Tsukamoto K, Hashimoto K. Cell surface expression of MR1B, a splice variant of the MHC class I-related molecule MR1, revealed with antibodies. Biochem Biophys Res Commun (2014) 443:422-7. doi:10.1016/j. bbrc.2013.11.096

53. Sims JE, Smith DE. The IL-1 family: regulators of immunity. Nat Rev Immunol (2010) 10:89-102. doi:10.1038/nri2691

54. Kurioka A, Van Wilgenburg B, Javan RR, Hoyle R, Van Tonder AJ, Harrold CL, et al. Diverse Streptococcus pneumoniae strains drive a mucosal-associated invariant T-cell response through major histocompatibility complex class I-related molecule-dependent and cytokine-driven pathways. J Infect Dis (2018) 217:988-99. doi:10.1093/infdis/jix647

55. Dias J, Sobkowiak MJ, Sandberg JK, Leeansyah E. Human MAIT-cell responses to Escherichia coli: activation, cytokine production, proliferation, and cytotoxicity. J Leukoc Biol (2016) 100:233-40. doi:10.1189/jlb.4TA0815-391RR

56. Bacher A, Eberhardt S, Fischer M, Kis K, Richter G. Biosynthesis of vitamin b2 (riboflavin). Аnnu Rev Nutr (2000) 20:153-67. doi:10.1146/annurev. nutr.20.1.153

57. Demain AL. Riboflavin oversynthesis. Annu Rev Microbiol (1972) 26:369-88. doi:10.1146/annurev.mi.26.100172.002101

58. Eckle SB, Birkinshaw RW, Kostenko L, Corbett AJ, Mcwilliam HE, Reantragoon R, et al. A molecular basis underpinning the $\mathrm{T}$ cell receptor heterogeneity of mucosalassociated invariant T cells. J Exp Med (2014) 211:1585-600. doi:10.1084/ jem.20140484

59. Soudais C, Samassa F, Sarkis M, Le Bourhis L, Bessoles S, Blanot D, et al. In vitro and in vivo analysis of the gram-negative bacteria-derived riboflavin precursor derivatives activating mouse mait cells. J Immunol (2015) 194:4641-9. doi:10.4049/jimmunol.1403224
60. Hartmann N, Mcmurtrey C, Sorensen ML, Huber ME, Kurapova R, Coleman FT, et al. Riboflavin metabolism variation among clinical isolates of Streptococcus pneumoniae results in differential activation of MAIT cells. Am J Respir Cell Mol Biol (2018) 58(6):767-76. doi:10.1165/rcmb.2017-0290OC

61. Meermeier EW, Laugel BF, Sewell AK, Corbett AJ, Rossjohn J, Mccluskey J, et al. Human TRAV1-2-negative MR1-restricted T cells detect S. pyogenes and alternatives to MAIT riboflavin-based antigens. Nat Commun (2016) 7:12506. doi:10.1038/ncomms12506

62. Johansson MA, Bjorkander S, Mata Forsberg M, Qazi KR, Salvany Celades M, Bittmann J, et al. Probiotic Lactobacilli modulate Staphylococcus aureusinduced activation of conventional and unconventional T cells and NK cells. Front Immunol (2016) 7:273. doi:10.3389/fimmu.2016.00273

63. Correa-Oliveira R, Fachi JL, Vieira A, Sato FT, Vinolo MA. Regulation of immune cell function by short-chain fatty acids. Clin Transl Immunology (2016) 5:e73. doi:10.1038/cti.2016.17

64. Park J, Kim M, Kang SG, Jannasch AH, Cooper B, Patterson J, et al. Shortchain fatty acids induce both effector and regulatory $\mathrm{T}$ cells by suppression of histone deacetylases and regulation of the mTOR-S6K pathway. Mucosal Immunol (2015) 8:80-93. doi:10.1038/mi.2014.44

65. Keller AN, Eckle SB, Xu W, Liu L, Hughes VA, Mak JY, et al. Drugs and druglike molecules can modulate the function of mucosal-associated invariant T cells. Nat Immunol (2017) 18:402-11. doi:10.1038/ni.3679

66. Paul D, Achouri S, Yoon YZ, Herre J, Bryant CE, Cicuta P. Phagocytosis dynamics depends on target shape. Biophys J (2013) 105:1143-50. doi:10.1016/j. bpj.2013.07.036

67. Hostetter MK. Serotypic variations among virulent pneumococci in deposition and degradation of covalently bound C3b: implications for phagocytosis and antibody production. J Infect Dis (1986) 153:682-93. doi:10.1093/ infdis/153.4.682

68. Melin M, Jarva H, Siira L, Meri S, Kayhty H, Vakevainen M. Streptococcus pneumoniae capsular serotype $19 \mathrm{~F}$ is more resistant to C3 deposition and less sensitive to opsonophagocytosis than serotype 6B. Infect Immun (2009) 77:676-84. doi:10.1128/IAI.01186-08

69. Salerno-Goncalves R, Rezwan T, Sztein MB. B cells modulate mucosal associated invariant T cell immune responses. Front Immunol (2014) 4:511. doi:10.3389/fimmu.2013.00511

70. Takata H, Naruto T, Takiguchi M. Functional heterogeneity of human effector CD8+ T cells. Blood (2012) 119:1390-8. doi:10.1182/blood-201103-343251

71. Becattini S, Latorre D, Mele F, Foglierini M, De Gregorio C, Cassotta A, et al. T cell immunity. Functional heterogeneity of human memory CD4(+) T cell clones primed by pathogens or vaccines. Science (2015) 347:400-6. doi:10.1126/science. 1260668

72. Cheuk S, Schlums H, Gallais Serezal I, Martini E, Chiang SC, Marquardt N, et al. CD49a expression defines tissue-resident CD8+ T cells poised for cytotoxic function in human skin. Immunity (2017) 46:287-300. doi:10.1016/j. immuni.2017.01.009

Conflict of Interest Statement: The authors declare that the research was conducted in the absence of any commercial or financial relationships that could be construed as a potential conflict of interest.

Copyright $\odot 2018$ Dias, Boulouis, Sobkowiak, Lal, Emgård, Buggert, Parrot, Gorin, Leeansyah and Sandberg. This is an open-access article distributed under the terms of the Creative Commons Attribution License (CC BY). The use, distribution or reproduction in other forums is permitted, provided the original author(s) and the copyright owner(s) are credited and that the original publication in this journal is cited, in accordance with accepted academic practice. No use, distribution or reproduction is permitted which does not comply with these terms. 